\title{
ADOÇÃO DE CRIANÇAS MAIORES: SOBRE ASPECTOS LEGAIS E CONSTRUÇÃO DO VÍNCULO AFETIVO
}

\author{
Letícia Víer Machado \\ Universidade Federal de Santa Catarina \\ Rodrigo Ramires Ferreira \\ Universidade Estadual de Maringá \\ Paulo César Seron \\ Universidade Estadual de Maringá
}

\begin{abstract}
Resumo
O tema da adoção de crianças maiores faz parte de um contexto de mudanças profundas na concepção de família. A adoção de crianças maiores refere-se à adoção de crianças acima de dois anos e ainda é preterida pelos adotantes brasileiros. Utilizando-se da metodologia de pesquisa documental teórica, analisamos a produção da legislação brasileira em termos de "adoção tardia". Discutimos os impasses que emergem na construção do vínculo entre pais e filhos maiores adotados e algumas contribuições teóricas sobre o estabelecimento dessa relação.
\end{abstract}

Palavras-chave: adoção tardia; família; estatuto da criança e do adolescente; psicologia.

\section{OLDER CHILDREN ADOPTION: ABOUT LEGAL ISSUES AND EMOTIONAL LINK CONSTRUCTION}

\begin{abstract}
Older children adoption is one matter among an entire context of profound changes in the concept of family. Older children adoption is the adoption of children over the age of two; such type of adoption is still highly disregarded by Brazilian adopters. By using theoretical documentary research methodology, we analysed the Brazilian law on older children adoption. Treating the impasses emerged from the construction of emotional links between parents and older children adoptees and the theoretical contributions psychology may adjoin to this establishing relationship.
\end{abstract}

Keywords: older children adoption; family; child and adolescent statute; psychology.

\section{ADOPCIÓN DE NIÑOS MAYORES: SOBRE ASPECTOS LEGALES Y CONSTRUCIÓN DEL ENLACE AFECTIVO}

\section{Resumen}

El tema de la adopción de niños mayores es parte de un contexto de profundos cambios en el concepto de familia. La adopción de niños mayores se refiere a la adopción de niños con más de dos años, y todavía es preterida por los adoptantes brasileños. Utilizando de la metodología de la investigación documental de carácter teórico, se analizó la producción de la legislación brasileña en términos de "adopción tardía." Nuestro objetivo es discutir los dilemas que surgen en la creación del enlace entre padres e hijos adoptivos mayores y algunas de las principales contribuciones teóricas sobre el establecimiento de esta relación.

Palabras clave: adopción tardía; familia; Estatuto de niños y adolescentes; psicología. 


\section{INTRODUÇÃO}

O tema da adoção tardia faz parte de um contexto de mudanças profundas na concepção de família. Configurações familiares estão sendo constantemente recriadas e são alvo de debates no meio acadêmico, na mídia, nas instituições e na sociedade em geral. Nesse contexto, a adoção chamada "tardia" questiona e denuncia a família ideal, sonhada, ao mesmo tempo em que chama para a família real, vivida.

Historiadores têm demonstrado já há muito tempo o caráter histórico da infância e da instituição familiar. O historiador francês Philippe Ariès (1973), em sua célebre obra "História Social da Infância e da Família", discorre sobre essa categoria historicamente inventada, a figura criada da "criança". Esses dois construtos históricos, família e infância, se uniram de maneira simbiótica para formar a família nuclear burguesa, dominante ainda no imaginário social como o modelo ideal de família: pai, mãe e filhos biológicos.

A modalidade da adoção "tardia" se configura como adoção de crianças acima de dois anos de idade e é também conhecida como adoção de crianças maiores, ou adoção moderna (Costa \& Rossetti-Ferreira, 2007). Portanto, parece-nos inadequado falar de "adoção tardia" quando já se estabeleceu que não se trata de uma oposição entre o tempo ideal para adotar (um recémnascido ou um bebê) e o tempo "tardio", ultrapassado. Por esse motivo, doravante utilizar-se-á a denominação "adoção de crianças maiores", sem tampouco fazer distinção, nesse momento, entre criança (0-12 anos) e adolescente (12-18 anos), englobando todos no conceito "criança", para fins práticos conceituais.

Ao abordar o processo de adoção, é preciso considerar as peculiaridades no desenvolvimento da criança, que possivelmente convive com um histórico de abandonos sucessivos, sejam eles materiais, morais e/ou afetivos. Para Winnicott (1987) o processo de transição de um local de convivência para outro para uma criança é recheado de angústias, seja de uma família a um abrigo e de um abrigo à uma outra família existe uma ameaça de perda de sentimentos e até mesmo de pertencimento levando a maior fragilidade de laços de confiança, de suporte psíquico ou ainda, nos termos de Bion (1971), da função de continência para as experiências ansiogênicas da primeira infância em crianças que sofreram abandono e viveram muito tempo abrigadas. Estes deverão ser criados e internalizados a partir das novas relações estabelecidas entre a criança e seus pais.

Tornar-se pai e mãe, por outro lado, também apresenta especificidades na adoção de crianças maiores. Longe de ser uma "parentalidade de segunda categoria", para utilizar a expressão de Costa e Rossetti-Ferreira (2007), exige romper com o projeto narcísico da parentalidade e se orientar para o conhecimento do outro, uma alter-idade, já portadora de uma história. Urge 
considerar, portanto, que o exercício da parentalidade na adoção de crianças maiores comporta também a adoção de uma história, de uma subjetividade própria da criança, já constituída, trabalhando constantemente na construção de um vínculo de confiança com aquela. É por esse viés que a investigação teórica será conduzida.

Em relação aos aspectos legais, no Brasil a adoção é regulamentada pelo Estatuto da Criança e do Adolescente, que teve suas disposições alteradas pela Lei no 12.010, em vigor desde novembro de 2009 e conhecida como "Nova lei da adoção". Esta, ao alterar disposições do ECA e do Código Civil de 2002, incentiva a adoção daqueles que outrora foram percebidos como preteridos: crianças maiores, com necessidades especiais, negros, índios, entre outros. O Artigo 87, parágrafo VII, do Estatuto da Criança e do Adolescente (Lei n 8.069/1990) incentiva e enfatiza "o acolhimento sob forma de guarda de crianças e adolescentes afastados do convívio familiar e à adoção, especificamente interracial, de crianças maiores ou de adolescentes, com necessidades específicas de saúde ou com deficiências e de grupos de irmãos" (grifo nosso) além do Plano Nacional de Convivência Familiar e Comunitária (PNCFC) que visa romper com a institucionalização de crianças e adolescentes.

Essa nova regulamentação, somada às mudanças estruturais na sociedade contemporânea, clama pela mudança do perfil dos adotados e dos adotantes no Brasil. Atualmente, a mudança ainda é tímida, já que $95 \%$ dos habilitados para adotar ainda querem crianças de até dois anos, brancas e do sexo feminino, como demonstra o Cadastro Nacional de Adoção (CNA), instituído também pela Lei 12.010/2009 (Mudança de Foco, 2012).

A partir das considerações expostas, somadas à experiência prática cotidiana da Psicologia em um Núcleo de Assistência Jurídica e Psicológica no que tange aos processos de adoção, surgem questionamentos que motivam a realização da pesquisa em tela: o que existe na legislação brasileira sobre a adoção de crianças maiores? Qual o papel da família na construção do psiquismo da criança e que dificuldades poderiam surgir nesse processo no caso de adoção de crianças maiores, considerando as falhas básicas que ela pode ter experienciado no decorrer de seu desenvolvimento? Por último, pontuamos algumas possíveis dificuldades na construção do vínculo afetivo com crianças maiores adotadas e sinalizamos a importância da preparação psicológica para a adoção.

Almeja-se, sobretudo, levantar hipóteses e produzir reflexões sobre o tema. Entende-se a impossibilidade de esgotar a discussão, considerando a escassez de produções científicas na área e a dificuldade de acesso às experiências infantis e vivências em relação ao processo de adoção. Entretanto, o que se pretende é tratar a questão na esfera teórica, contemplando o adotado nesse processo, como têm orientado o Estatuto da Criança e do Adolescente no Brasil, em consonância com outros países (Costa \& Rossetti-Ferreira, 2007), no 
sentido de contemplar o melhor interesse da criança, respeitando os princípios da doutrina da proteção integral e encontrando pais para filhos, e não filhos para pais.

\section{Configurações familiares contemporâneas}

O movimento de resgate da história da infância e da família transcende os limites deste trabalho. Contudo, cabe ressaltar, como já havíamos introduzido, que "infância" e "família" são conceitos históricos, e a família é uma instituição histórica. Isso significa desnaturalizar a concepção de uma família ideal, imutável e atemporal, e assumir a historicidade com toda a carga de mudanças e reviravoltas que a habitam.

O modelo de família ideal burguesa construído ao longo da história e descrito por Ariès (1973) parece não encontrar eco na situação brasileira, se analisada a partir dos dados geográficos dos quais dispomos. Na Pesquisa Nacional por Amostras de Domicílios, realizada em 2014, constatou-se que as configurações familiares brasileiras distribuíam-se nos seguintes grupos: unipessoal, 13,5\%; Casal sem filhos: 19,4\%; Casal com filhos: 44\%; Mulheres sem cônjuges e com filhos: 16,5\%, outros tipos: 6,3\% (IBGE 2014).

Esses números, para além de seu valor estatístico, convidam a repensar o conceito de família na legislação brasileira e na sociedade como um todo. Sendo assim, reiteramos que a família é definida pela Constituição de 1988, no Art. 226, parágrafo 4, como "a comunidade formada por qualquer um dos pais e seus descendentes". Vemos que, na Carta Magna, ainda rege a concepção de família nuclear burguesa.

Também no Estatuto da Criança e do Adolescente (ECA), em seu Art. 25, a família natural é definida de maneira semelhante, ou seja, como "a comunidade formada pelos pais ou qualquer deles e seus descendentes".

Como enfatiza o Plano Nacional de Promoção, Proteção e Defesa dos Direitos de Crianças e Adolescentes à Convivência Familiar e Comunitária (2006), estas definições têm em comum a centralidade dos vínculos de filiação legal, seja ela de origem natural ou adotiva. Entretanto, acabam por desconsiderar os diferentes arranjos familiares passíveis de compor tais vínculos entre pais e filhos.

Sendo assim, a maneira mais adequada de definir "família" tal como ela se apresenta hoje no bojo da sociedade brasileira inclui dizer que as alianças que a sustentam são formadas por laços de consanguinidade, porém também de afinidade conforme o PNCFC (2006):

Esses laços são constituídos por representações, práticas e relações que implicam obrigações mútuas. Por sua vez, estas obrigações são organizadas de acordo com a faixa etária, as relações de geração e de gênero, que definem o status da pessoa dentro do sistema de relações familiares (p. 25). 
Considerar a família a partir desse enfoque é reconhecer a existência de famílias desidealizadas, reais, entre diversos grupos sociais. Assim, ampliam-se também a natureza dos vínculos, que se estendem da parentalidade e filiação para outras combinações possíveis, configurando o que o Estatuto da Criança e do Adolescente legitima como "família extensa", ou seja, pessoas com as quais a criança e o adolescente mantêm laços de afinidade e afetividade, para além do vínculo consanguíneo.

Para o Plano supracitado, a importância de centralizar a definição de "família" nos vínculos, em detrimento do "domicílio", facilita a garantia de direitos. Isso porque não habitar o mesmo domicílio, porém possuir um vínculo familiar, não isenta o membro da família de suas obrigações legais, como ocorre com pais ou mães que não dividem o mesmo teto com seus filhos, porém não estão imunes de suas responsabilidades parentais (PNCFC, 2006).

Por último, a partir do exposto fica evidente a urgência da desmistificação da família ideal, englobando os arranjos familiares que têm se tornado cada vez mais comuns na sociedade. Assim, decreta-se o declínio de alguns ideais que sustentaram a modernidade, como a família nuclear e patriarcal, para dar espaço à manifestação de uma realidade, de um modo de ser e de estar no mundo. É preciso dar ênfase às funções que essa família exerce ou deve exercer (de proteção, de cuidado, de educação, de socialização e de cidadania, entre outras), em detrimento de sua estrutura, que já não é unívoca e passível de delimitação.

Como consequência, colocamos em questão os conceitos de "família desestruturada" ou "família normal", e convidamos o leitor a um pensamento crítico, que permita discutir caso a caso, considerando o arranjo familiar em tela.

\section{A legislação atual sobre adoção no Brasil: contemplando os preteridos}

Restringimos nossa pesquisa documental em termos de legislação sobre adoção a três recentes documentos que representaram avanços na adoção de crianças maiores e adolescentes para o país, fazendo ainda um recorte de modo a priorizar questões referentes à adoção. São eles: o Estatuto da Criança e do Adolescente (ECA), o Plano Nacional de Promoção, Proteção e Defesa dos Direitos de Crianças e Adolescentes à Convivência Familiar e Comunitária (PNCFC), de 2006, e a Lei de Adoção (Lei no 12.010/2009).

\section{O Estatuto da Criança e do Adolescente}

É consenso o reconhecimento do avanço que representou o Estatuto da Criança e do Adolescente para o Brasil. Isso porque ele representa os direitos das crianças e adolescentes, outrora considerados como aqueles que não tinham voz. A partir de um processo histórico de transformações no seio da família, da sociedade e do Estado do qual o ECA fez parte, as crianças e adolescentes passam a ser reconhecidos como sujeitos de direitos. O mesmo progresso em termos de legislação se efetuou no que tange à adoção. 
Esta é contemplada no ECA na Subseção IV, artigos 39 à 52-D. Em linhas gerais, o ECA classifica a adoção como medida excepcional e irrevogável, quando esgotados os recursos para a manutenção da criança ou do adolescente na família natural ou extensa (Art. $39 \S 1^{\circ}$ ). A partir de então, o filho adotado tem direitos e deveres equiparados aos de filhos biológicos.

Com o ECA, a adoção é precedida de um estágio de convivência, acompanhado por equipe multiprofissional, dispensado apenas se o adotando já estiver sob a tutela ou guarda do adotante por um tempo que permita avaliar a constituição do vínculo entre ambos (Art. $46 \$ 1^{\circ}$ ). Além disso, firmado o vínculo entre pais e filhos por meio de sentença judicial, sem produzir certidões ou outros documentos que atestem a natureza do vínculo, nada pode desfazê-lo, nem mesmo a morte dos adotantes. É, como dissemos, um vínculo irrevogável.

Em síntese, o ECA, além de representar o alinhamento com políticas internacionais, na medida em que o Brasil se faz signatário da Convenção sobre os Direitos da Criança, em 1989, no que tange aos direitos da criança e do adolescente, trata dos processos de adoção reafirmando a legitimidade do vínculo e a necessidade de cuidados e acompanhamento especiais no decorrer de sua constituição. Reconhece a peculiaridade da adoção, firmando ainda a necessidade do incentivo à adoção inter-racial, de crianças maiores e de adolescentes, com necessidades específicas de saúde ou com deficiência e de grupos de irmãos (Art. 87).

Plano Nacional de Promoção, Proteção e Defesa dos Direitos de Crianças e Adolescentes à Convivência Familiar e Comunitária (PNCFC).

O Plano foi idealizado pelo Governo Federal para garantir a convivência familiar e comunitária enquanto direito de crianças e adolescentes. Portanto, traça metas e objetivos para serem atingidos a curto, médio e longo prazo, garantindo a criação e fortalecimento de políticas públicas voltadas à família e ao fortalecimento dos vínculos familiares.

Por meio de uma articulação com diferentes esferas do Governo, com o CONANDA (Conselho Nacional dos Direitos da Criança e do Adolescente) e com o CNAS (Conselho Nacional de Assistência Social) e de uma parceria com a sociedade civil organizada, o Plano foi estruturado a partir do paradigma da proteção integral.

Assim, o objetivo maior desse Plano foi dar subsídios para o fortalecimento das políticas públicas de atenção à família para fortalecer os vínculos familiares e comunitários de crianças e adolescentes. Nesse intuito, a colocação em família substituta é medida excepcional, que deve se dar prioritária e definitivamente por meio da adoção.

Alinhado a outras legislações e normativas internacionais de garantia dos direitos humanos, o Plano privilegia o melhor interesse da criança e do adolescente, o respeito a sua opinião e a não discriminação. Além do que, o 
PNCFC (2006) prioriza a qualidade dos vínculos familiares, independente do arranjo familiar dentro do qual este se firma:

A ênfase no vínculo de parentalidade/filiação, respeita a igualdade de direitos dos filhos, independentemente de sua condição de nascimento, imprimindo grande flexibilidade na compreensão do que é a instituição familiar, pelo menos no que diz respeito aos direitos das crianças e adolescentes. Torna-se necessário desmistificar a idealização de uma dada estrutura familiar como sendo a "natural", abrindo-se caminho para o reconhecimento da diversidade das organizações familiares no contexto histórico, social e cultural. Ou seja, não se trata mais de conceber um modelo ideal de família, devendo-se ultrapassar a ênfase na estrutura familiar para enfatizar a capacidade da família de, em uma diversidade de arranjos, exercer a função de proteção e socialização de suas crianças e adolescentes ( $p$. 24).

Portanto, ao desmistificar o modelo ideal de família burguesa, abre-se espaço para novas concepções de família, para o diálogo e também para a desmistificação da adoção, sobretudo de crianças maiores, visto que a função da família de proteção e de socialização independe de seu arranjo.

O Plano ainda recupera parte da história da adoção na legislação brasileira para fundamentar suas ações. Salienta que a adoção é uma importante ferramenta para legitimar o direito à convivência familiar e comunitária (PNCFC, 2006). Além disso, resgata o argumento da doutrina da proteção integral e o melhor interesse da criança e do adolescente para reiterar a importância da adoção daqueles que são geralmente preteridos pelos adotantes, quais sejam: "grupos de irmãos, crianças maiores e adolescentes, com deficiência, com necessidades específicas de saúde, afrodescendentes, pertencentes a minorias étnicas e outros" (PNCFC, 2006, p. 44, grifo nosso).

Outros pontos importantes sobre a adoção são contemplados no documento. Entre eles, a frequência da adoção irregular no país, seja ela a adoção intuito personae (quando os pais biológicos designam o adotante) ou a adoção à brasileira (registrar filho de outrem em seu nome). A partir dessas considerações, o Plano se posiciona em relação à adoção, ressaltando a necessidade de políticas preventivas que assegurem a construção do vínculo desde a gravidez, a orientação para os futuros pais, a prevenção à violência e ao abandono, entre outras medidas (PNCFC, 2006).

Além disso, o documento reafirma a excepcionalidade da medida de adoção, em consonância com o ECA, medida que deve ser precedida da tentativa da reintegração familiar. Também reitera a necessidade de acompanhamento da Justiça nos casos de Acolhimento Institucional e a atualização constante do cadastro de adoção. Assim, percebe-se que alguns aspectos práticos e simples são também sinônimo de garantia de direitos.

O Plano ainda contempla o outro lado da adoção, ou seja, os desejos e necessidades dos pais que entregam seus filhos para adoção. Considera a necessidade de atendimento diferenciado em todas as esferas para a mãe que 
deseja entregar seu filho para adoção, respeitando-a e fornecendo subsídios jurídicos, psicológicos, de saúde e de assistência social (PNCFC, 2006).

No que tange à nossa temática em questão, o documento reforça a necessidade de conscientização da sociedade para a importância da adoção dos preteridos, entre os quais crianças maiores e adolescentes, tal como segue no PNCFC (2006):

[...] conscientização e sensibilização da sociedade acerca da necessidade de se garantir o direito à convivência familiar e comunitária às crianças e aos adolescentes comumente preteridos pelas pessoas que se candidatam à adoção - crianças maiores e adolescentes, afrodescendentes e oriundos de minorias étnicas, com deficiência ou necessidades específicas de saúde, grupos de irmãos, dentre outros; $n$ ) busca ativa de famílias para estas crianças e adolescentes que, por diversos fatores, têm sido preteridos pelos adotantes, fomentando as possibilidades de adoção nacional para os mesmos; o) uma vez esgotadas as possibilidades de manutenção na família de origem, agilização dos procedimentos, por parte da Justiça, de modo a prevenir prolongamento desnecessário da permanência no serviço de acolhimento [...] (p. 46).

Por fim, o documento reforça a necessidade do encontro entre desejos e necessidades de ambas as partes, filhos e pais; o papel central do Estado na proteção, defesa e garantia ao direito de convivência familiar e a centralidade dos interesses da criança, para que essa possa se desenvolver plenamente no seio de uma família (PNCFC, 2006).

\section{A "nova" Lei de Adoção}

A Lei no 12.010/2009 trouxe importantes contribuições e avanços em matéria de adoção de crianças maiores e adolescentes no país. Seu feito inédito consistiu na modificação de disposições sobre a adoção, dispersas entre o Estatuto da Criança e do Adolescente e o Código Civil de 2002. É, portanto, uma Lei modificadora, cujas contribuições já foram explanadas na seção sobre o ECA.

A estas, acrescentam-se as disposições do Art. 197-C, que reitera a obrigatoriedade do estudo psicossocial, elaborado por equipe interdisciplinar a serviço da Justiça da Infância e da Juventude, a fim de aferir a capacidade dos postulantes à paternidade/maternidade. Além do que, afirma o mesmo artigo a obrigatoriedade da participação dos postulantes à adoção em programas preparatórios, incluindo a preparação psicológica e o estímulo à adoção interracial, de crianças maiores e adolescentes, com necessidades de saúde, deficiência e grupos de irmãos.

Assim, reaparece na Lei, ainda que de maneira tímida, a preocupação para com o estímulo à adoção de crianças maiores e adolescentes.

Adoção de crianças maiores: situação atual no Brasil

A nova Lei de Adoção, somada às mudanças estruturais na sociedade contemporânea, revela a necessidade da mudança no perfil de crianças e 
aodlescentes escolhidos pelos adotantes no Brasil, aproximando-os cada vez mais do perfil das crianças e adolescentes adotáveis. Se as configurações familiares estão paulatinamente se diferenciando do modelo unívoco de família nuclear burguesa, branca, composta por pai, mãe e filhos, urge também desvincular a adoção deste modelo em declínio.

Entretanto, a procura pelos filhos "perfeitos", brancos, ainda bebês (para que cresçam no seio da família como "filhos biológicos") ainda é predominante. 0 que se constata é que atualmente, a mudança ainda é tímida, já que $95 \%$ dos habilitados para adotar ainda querem crianças que se enquadrem no modelo ideal, como demonstra o Cadastro Nacional de Adoção (CNA), instituído também pela Lei 12.010/2009 (Mudança de Foco, 2012).

Outro grave empecilho no sentido da adoção de crianças maiores é a morosidade nos processos de destituição do poder familiar, sem os quais uma adoção não pode ser levada a termo. Assim, priva-se a criança e o adolescente do direito à convivência familiar, já que segundo o PNCFC (2006) "toda criança e adolescente cujos pais são falecidos, desconhecidos ou foram destituídos do poder familiar têm o direito a crescer e se desenvolver em uma família substituta e, para estes casos, deve ser priorizada a adoção que Ihes atribui a condição de filho e a integração a uma família definitiva." (p. 73).

O Conselho Nacional de Justiça (CNJ) estima que 45.531 crianças estejam em centros de acolhimento em todo o País. Dessas, apenas 5.469 estão aptas à adoção segundo dados de acesso público no portal da instituição. No mesmo sentido, o Plano Nacional de Promoção, Proteção e Defesa do Direito das Crianças e Adolescentes à Convivência Familiar e Comunitária ressalta que o perfil das crianças abrigadas em instituições não vão ao encontro dos desejos da sociedade para adoção, já que a população abrigada é em sua maioria do sexo masculino, afrodescendentes e mais velhos (entre 7 e 15 anos - 61,3\%) (PNCFC, 2006).

Além do que, o mesmo documento revela a situação paradoxal das crianças e adolescentes abrigados, que não são adotáveis por possuírem família e vínculos com seus familiares, ao mesmo tempo que estão judicialmente privados desse contato com a família.

Portanto, embora reconhecidos avanços tenham sido alcançados em termo de legislação, a prática da adoção ainda enfrenta graves desafios, uma vez que estão envolvidos nesse processo preconceitos, representações sociais de família, dificuldades no âmbito judiciário e, sobretudo, a realidade das crianças adotáveis no país. Vincular pais e filhos não é tarefa simples de se realizar. Estatísticas atuais demonstram que a adoção de crianças maiores pode ser um processo doloroso, permeado de dificuldades. A fim de melhor pontuá-las e as esclarecer, revisitamos alguns conceitos da psicanálise sobre o desenvolvimento e a constituição do eu para, na sequência, problematizar casos reais de insucesso de uma adoção dita tardia. 
A família como núcleo estruturante do sujeito: o eu se constitui pelo outro

Reconhecer o direito fundamental da criança e do adolescente à convivência familiar e comunitária é atribuir à família papel central no desenvolvimento e na estruturação do sujeito, reconhecendo ainda a historicidade desse fenômeno. Independente dos moldes em que é construída, reconhecemos que a criança - e, mais especificamente, o bebê - se constitui pelo contato com o outro.

Essa perspectiva foi disseminada no campo da psicologia do desenvolvimento e foi largamente incorporada nas políticas públicas brasileiras voltadas à garantia dos direitos de convivência familiar, refletindo consequentemente na elaboração do PNCFC de 2006. Neste, ratifica-se o papel da família como primeiro núcleo de socialização da criança: é no seio desta que se estabelecem as primeiras identificações da criança, vulnerável e inteiramente dependente - biológica, social e psicologicamente - daqueles que dela se ocupam.

$\mathrm{Na}$ psicanálise, o pediatra e psicanalista infantil Donald Winnicott sistematizou os conhecimentos acerca da dependência - absoluta e relativa pelas quais o bebê passa no início de sua vida. A tese de que o sujeito se constitui pelo outro ampara-se nesta lente teórica: inicialmente, o bebê não é outra coisa senão uma unidade com o ambiente, com as relações que estabelece no mundo (De Conti, 2010).

De Conti (2010), baseada na teoria winnicottiana, assim formula esse postulado da dependência bebê-ambiente:

Seja quando é tomado nos braços para ser trocado de roupa ou alimentado, seja embalado para dormir ou simplesmente acalentado quando chora, forma-se inexoravelmente um par que existe em referência mútua, da perspectiva de quem os observa, mas com repercussões muito específicas para o bebê que está começando a se constituir como pessoa (p. 120).

Em outras palavras, é através dos primeiros cuidados que recebe do outro que o bebê desenvolve paulatinamente o sentimento de ser e de existir, na medida em que se sente cuidado e seguro pelo ambiente que o envolve. Isso significa que ao desenvolvimento é imprescindível o contato com um ambiente favorecedor, que propicie condições de desenvolvimento do self, ainda que ocorram falhas (frustrações).

Mais além, nos primeiros anos de vida, a família continua a assumir papel central no desenvolvimento. No momento em que a criança inicia a socialização fora do ambiente familiar, é a família ela própria a mediadora da transição para o universo social, auxiliando na introjeção de "regras, limites e proibições necessárias à vida em sociedade" (PNCFC, 2006, p. 27). Do mesmo modo, como pontuado no PNCFC (2006), a família pode contribuir ou não para a construção dos vínculos da criança, para o sentimento de autoconfiança e confiança no 
meio, para o controle dos impulsos e para a capacidade da criança de tolerar frustrações, entre tantos outros aspectos.

Essa intervenção familiar, seja da família biológica, adotiva ou extensa, influenciará na construção da personalidade do sujeito que se desenvolve. Fazendo referência à abordagem de autores da vertente psicanalítica tais como Winnicott, Spitz, Dolto e Bowlby, entre outros, o Plano de promoção à convivência familiar e comunitária pelo qual viemos nos pautando nesse texto do PNCFC (2006) afirma que a separação da criança ou do adolescente do convívio familiar, ou até mesmo sua institucionalização,

[...] pode repercutir negativamente sobre seu desenvolvimento, sobretudo quando não for acompanhada de cuidados adequados, administrados por um adulto com o qual possam estabelecer uma relação afetiva estável, até que a integração ao convívio familiar seja viabilizada novamente (p. 31).

Assim, sustentados na assertiva já fundamentada de que a constituição dos primeiros vínculos de afeto e afinidade que balizarão as relações ulteriores da criança e do adolescente é influenciada pelo núcleo de convívio familiar que envolve a criança, desembocamos na reflexão que se segue, sobre as possíveis (e não dificilmente realizáveis) dificuldades da adoção de crianças maiores.

Lembrando que as crianças e adolescentes inscritos no Cadastro Nacional de Adoção, ou seja, as crianças e adolescentes chamados de adotáveis, quando não inseridos em famílias substitutas provavelmente estarão em instituições de acolhimento, urge refletir sobre o desenvolvimento e as consequências que a privação familiar pode produzir nesse momento crucial que são os primeiros anos de vida.

Possíveis dificuldades no processo de constituição dos vínculos entre adotantes e adotados

Winnicott desenvolveu parte de seus estudos no período da $2^{a}$ Guerra Mundial, estudando as consequências da privação materna para crianças afastadas do lar nos grandes centros e enviadas para cidades interioranas, bem como a relação entre privação e delinquência.

Em Privação e delinquência Winnicott (1987), discorre sobre as dificuldades da inserção de crianças em outros lares, afirmando de acordo com suas experiências nos tempos de guerra, que as crianças afastadas do próprio lar, composto por sua família biológica, não se adaptavam facilmente a outro ambiente familiar porque já haviam formulado em sua mente um conceito de lar diferente daquela realidade que lhes era apresentada.

Ao aplicar esse exemplo à presente discussão, consideramos que as crianças maiores adotáveis, em sua maioria, passam por um longo período de institucionalização. Ou ainda, que essas instituições de acolhimento vêm a ocupar esse lugar na mente da criança, preenchendo o conceito de "lar". Posteriormente, quando adotadas, as crianças maiores e/ou adolescentes têm 
que reconstruir a concepção de lar a qual estavam habituadas, tarefa que pode ser árdua e dolorida.

No caso da institucionalização e adoção, podemos ainda pensar em crianças e adolescentes que não têm a experiência e consequente registro anterior do que constituiria um lar, necessitando, portanto, do que Winnicott (1978) denomina da "experiência de um lar primário" (p. 63).

Os estudos e observações de Winnicott (1987) das crianças a quem ele denominava de "evacuadas" por terem deixado forçosamente o lar em tempos de guerra trouxeram ainda outras contribuições. Exemplifica o autor que crianças que estiveram fora de um lar tiveram que exercer sobre si mesmas um forte autocontrole de seus impulsos que, ao encontrarem um lar, transferem o controle para os pais, podendo produzir comportamentos "agressivos e displicentes" (p. 56).

Portanto, para que ocorra a formação de um vínculo saudável entre pais e filhos adotivos, carregados de experiências de lares anteriores, é preciso que os pais compreendam sua importância como válvula de escape de impulsos e de agressividade de crianças maiores. Afinal, é para eles que a criança direcionará seus sentimentos ambivalentes, de amor e ódio, para garantir que dessa vez os pais sobreviverão, apesar de seus ataques. Segundo Winnicott (1987):

[...] para que uma criança possa descobrir a parte mais profunda de sua natureza, alguém terá que ser desafiado e até, por vezes, detestado; e quem, senão os próprios pais, poderá ser detestado sem haver o perigo de um rompimento completo do relacionamento? ( $p$. 57).

Por último, na esteira do conceito de posição depressiva em Melanie Klein, Winnicott considera a ambivalência amor e ódio essencial para o desenvolvimento dos sentimentos e para o aprendizado da reparação, isto é, da possibilidade de restaurar o objeto. Nas palavras de Winnicott (1987), "Sem uma pessoa a quem possa amar e odiar, a criança não pode chegar a saber amar e odiar a mesma pessoa e, assim, não pode descobrir seu sentimento de culpa nem o seu desejo de restaurar e recuperar" (p. 63-64).

$\mathrm{Na}$ adolescência, somados a esses desafios, outros devem ser trabalhados no processo de adoção. Dentre esses, pode-se mencionar a falta de referenciais para a construção identitária, para o desenvolvimento da autonomia e para a construção de projetos, se o adolescente encontra-se privado da convivência familiar (PNCFC, 2006).

Assim, revela-se fundamental a preparação para a adoção de crianças maiores e adolescentes institucionalizados, tanto dos adotantes quanto dos adotados. Nesse sentido, cabe ao psicólogo como integrante de uma equipe interprofissional no âmbito da justiça, alocado nas Varas da Infância e da Juventude ou nas Varas de Família, assessorar os operadores da justiça no processo de adoção. Em conjunto com assistentes sociais, o psicólogo transcende 
os aspectos legais da adoção para adentrar no campo dos aspectos afetivos, avaliar o ambiente familiar e a compatibilidade da adoção.

Ainda que não se possa garantir o sucesso de um processo de adoção, o trabalho preventivo e preparatório exercido pelos psicólogos no âmbito da justiça pode obter resultados proveitosos. Não obstante, o ECA não detalha como o trabalho de preparação pode ser feito, deixando apenas indicações para um trabalho que deve ser elaborado de acordo com as demandas da comarca e da população local.

Assim, o trabalho de preparação psicológica para a adoção deve ser realizado preferencialmente em grupo, no formato de grupos de apoio. 0 objetivo é a construção de espaços de troca de experiências, reflexão e discussão das expectativas e motivações dos pretendentes. Os conteúdos dos encontros podem incluir o luto por um filho biológico não nascido, infertilidade e elaboração de sentimentos ambivalentes que surgem durante o processo, como raiva, vergonham injustiça ou autopunição, no caso de um corpo que não corresponde ao desejo inconsciente do sujeito de ter filhos (Campos, 2010).

Nesse sentido, o trabalho de preparação psicológica para a adoção tensiona o desejo e os limites dos pretendentes, no intuito de construir ou amadurecer o projeto de adotar (Campos, 2010). Essa elaboração que precede a adoção permite burlar o registro imaginário dos sujeitos, no qual reside a imagem do filho idealizado narcisicamente, confrontando-os com o real e inscrevendo novos significados no registro simbólico. Afinal, na busca pela legitimação de seu desejo urgente de ter filhos, é comum que os pretendentes recusem aquele que não é semelhante, estabelecendo seus próprios critérios de exclusão como raça, gênero e, como viemos discutindo, idade.

Além do que, no que tange ao adotado, é importante considerar os significados por ele atribuídos à instituição de acolhimento na qual se encontra, assim como os sentimentos que definem sua relação com a instituição, seu conceito de lar e sua etapa de desenvolvimento. Pereira (citado por PNCFC, 2006, p. 31) destaca a importância de um desligamento gradativo da instituição de acolhimento, considerando que a adolescência "pode ser acompanhada de sentimentos de perda, frente à aproximação da separação, muitas vezes, do único referencial do qual o adolescente dispõe: os vínculos construídos na instituição".

\section{Devolução de crianças e abandono afetivo}

Poucas são as pesquisas relacionas à "devolução" de crianças adotadas. Tais práticas são mais recorrentes do que se pode imaginar e as poucas estatísticas existentes acerca do tema provêm das Varas da Infância e Juventude e das instituições de acolhimento. Vale salientar que a adoção é uma medida irrevogável e excepcional, e concede ao adotado a condição de filho sem qualquer discriminação. Entretanto, devoluções podem ocorrer durante o estágio 
de convivência, quando a adoção definitiva ainda não foi sentenciada, depois da adoção formalizada ou quando a família tem a guarda da criança.

Diferentes são os motivos que levam a uma pessoa a querer adotar: infertilidade, tentativa de salvar um relacionamento, caridade, e em muitos casos existe previamente o sonho com o filho ideal, que não será realizado pela criança real. Esse conflito entre o filho ideal e a criança real deve ser muito bem elaborado para que o vínculo a ser formado, não seja comprometido, ao ponto de ocorrer a devolução. Nesse sentido, "a adoção de uma criança ou de um adolescente exige capacidade de adaptação e a realização de um trabalho de luto, assim como um descolamento da criança real em relação à criança imaginária" (Levy, Pinho, \& Faria, 2009, p. 60).

A habilitação para adoção no país prevê um trabalho específico com os postulantes a adotantes, mas na maioria das vezes o judiciário não consegue acompanhar todos os processos. Muitas pessoas que na hora do cadastro pretendiam adotar um bebê acabam aceitando adotar crianças maiores, para não ter que esperar na fila por muito tempo, uma vez que poucos bebês estão disponíveis para adoção. Para Levy et al. (2009):

No procedimento de habilitação para adoção ainda não há a criança real; fala-se de um projeto, de desejos, fantasias, expectativas, preconceitos, ideais. Quando ocorre o encontro real com a criança, muitas outras questões costumam entrar em cena, como em toda situação de parentalidade. Os medos, fantasias e preconceitos, até então tratados de forma abstrata, ganham uma nova dimensão. Por vezes encontramos um pensamento de que os requerentes à adoção podem "experimentar a criança" e, se não gostarem do produto, se ela não corresponder ao filho idealizado, podem desistir da adoção, pois, legalmente, a adoção é irrevogável somente após a sentença do Juiz. Contudo, do ponto de vista psicológico, consideramos que os requerentes, ao levarem a criança para casa sob guarda provisória, estabelecem um compromisso ético em relação à adoção, principalmente nas situações de adoção tardia na qual houve visitações prévias (p. 63).

As justificativas para a devolução estão comumente ligadas à inadaptação da criança ao modelo ideal que os adotantes desejam, levando a uma culpabilização das crianças para que o vínculo não dê certo. São relatados "problemas" de comportamento e patologias que seriam "toleradas" em filhos biológicos mas não em filhos adotivos, uma vez que no imaginário parental, as crianças deveriam lhes prestar gratidão por adotá-las (Levy et al., 2009).

Por conseguinte, muitas crianças assumem a culpa pelo segundo abandono, mantendo no imaginário a ideia de que não são crianças suficientemente boas e perpetuando o discurso de que ela não serve para fazer parte de uma família. As crianças teriam então dois caminhos: enquadrar-se às expectativas ideais da família que a adota, ou então correr o risco de não se inserir nas relações familiares. 
Deve-se refletir a importância da preparação mais efetiva para o processo de adoção, em que o estágio de convivência seja acompanhado de perto, de forma mais efetiva do que acontece hoje, para que as atitudes tornem-se mais conscientes e tenha-se uma maior responsabilidade sobre as relações afetivas já efetivadas ou em construção (Levy et al., 2009).

\section{CONSIDERAÇÕES FINAIS}

Atualmente, a adoção de crianças maiores é regulamentada no Brasil pelo ECA, seguindo as disposições da Nova Lei de Adoção, de 2009. Essa lei modificadora sinalizou a necessidade de mudanças no perfil de crianças e adolescentes desejados pelos postulantes à adoção, estimulando a adoção interracial, de crianças maiores e adolescentes, com necessidades de saúde, deficiência e grupos de irmãos, frequentemente preteridos pelos futuros pais.

A inclusão na referida lei da obrigatoriedade da participação dos postulantes à adoção em programas preparatórios, inclusive de preparação psicológica, revela uma preocupação latente com o desafio de provocar uma mudança no entendimento das famílias postulantes à adoção, visto que há ainda uma grande procura por bebês com até um ano, brancos e do sexo feminino. Nesse sentido, a preparação psicológica pode auxiliar os futuros pais a amadurecerem seu projeto de adotar, ao elaborar o luto por um filho idealizado e dar suporte à produção de novos significados para a adoção.

Por outro lado, não se pode descartar a experiência prévia da criança ou adolescente adotado em instituições de acolhimento, frequentemente por longos e sucessivos períodos. Esse histórico, produtor de inseguranças em ambos - pais e filhos -, traz seus reflexos na criação e manutenção dos vínculos afetivos com a família adotante. Assim, a importância da elaboração dos conflitos gerados no estabelecimento dos vínculos deve ser ressaltada, a fim de que se possam contornar episódios de segundo abandono.

Afinal, desconstruir a ideia de que devem ser encontrados filhos para os pais é um caminho para a mudança no entendimento de que o que se busca são pais, famílias para crianças e adolescentes que já sofreram com o abandono afetivo, retirando delas a "culpa" pela não formação de vínculos.

\section{REFERÊNCIAS}

Ariès, P. (1973). História Social da Infância e da família. Rio de Janeiro: Zahar. Bion, W.R. (1971). Aprendendo com a experiência. Rio de Janeiro: Imago. 
Campos, N. (2010). Reflexões a partir do grupo de preparação para adoção: as angústias da espera e suas implicações na tarefa de luto pela infertilidade e pelo filho idealizado. Recuperado em 13 de junho de 2015 de: http://www.tjdft.jus.br/cidadaos/infancia-e-juventude/textos-eartigos/reflexoes-a-partir-do-grupo-de-preparacao-para-adocao-asangustias-da-espera-e-suas-implicacoes-na-tarefa-de-luto-pelainfertilidade-e-pelo-filho-idealizado/at download/file.

Conselho Federal de Psicologia. (2012). Mudança de foco nos processos de adoção reforça papel do psicólogo. Revista Diálogos, 9 (8), 36-39. Recuperado em 30 de janeiro de 2013 de http://site.cfp.org.br/wpcontent/uploads/2012/10/Dialogos8 23outubro.pdf

Costa, N. R. do A. \& Rossetti-Ferreira, M. C. (2007). Tornar-se pai e mãe em um processo de adoção tardia. Psicologia Reflexão e Crítica, 20 (13), 425-434. Recuperado em 30 de janeiro de 2013 de: http://www.scielo.br/pdf/prc/v20n3/a10v20n3.pdf.

De Conti, C. A. M. (2010). O papel do outro na constituição do psiquismo: um tema e duas abordagens em dialogia. Tese de Doutorado Programa de Pósgraduação em Educação da UNIMEP. Piracicaba - SP.

INSTITUTO Brasileiro de Geografia e Estatística IBGE. (2014). Pesquisa Nacional por Amostra de Domicílios. Síntese de Indicadores Sociais. Rio de Janeiro: IBGE. Recuperado em 14 de junho de 2015 de: ftp://ftp.ibge.gov.br/Indicadores Sociais/Sintese de Indicadores Sociais 2 014/pdf/familias.pdf

Lei 12.010, de 03 de agosto de 2009. (2009, 03 de agosto). Dispõe sobre adoção; altera as Leis nos 8.069, de 13 de julho de 1990 - Estatuto da Criança e do Adolescente, 8.560, de 29 de dezembro de 1992; revoga dispositivos da Lei no 10.406, de 10 de janeiro de 2002 - Código Civil, e da Consolidação das Leis do Trabalho - CLT, aprovada pelo Decreto-Lei $n^{\circ}$ 5.452, de $1^{\circ}$ de maio de 1943; e dá outras providências. Recuperado em 30 de janeiro de 2013, de http://www.planalto.gov.br/ccivil 03/ ato20072010/2009/lei/l12010.htm.

Lei 8.069, de 13 de julho de 1990. (1990, 13 de julho). Dispõe sobre o Estatuto da Criança e do Adolescente e dá outras providências. Recuperado em 30 de janeiro de 2013 de http://www.planalto.gov.br/ccivil 03/leis/L8069.htm.

Levy, L., Pinho, P. G. R., \& Faria, M. M. (2009) "Família é muito sofrimento": um estudo de casos de devolução de crianças. Psico, Rio de Janeiro, 1 (40), 5963. Recuperado em 30 de janeiro de 2013 de http://revistaseletronicas.pucrs.br/fo/ojs/index.php/revistapsico/article/vie $\mathrm{w} / 3730 / 4142$. 
Ministério do Desenvolvimento Social e Combate à Fome. Secretaria Especial dos Direitos Humanos. (2006). Plano Nacional de Promoção, Proteção e Defesa do Direito de Crianças e Adolescentes à Convivência Familiar e Comunitária. Brasília-DF.

Roudinesco, E. \& Plon, M. (1998). Dicionário de Psicanálise. Rio de Janeiro: Zahar.

Winnicott, D. W. (1987). Privação e Delinquência. São Paulo: Martins Fontes.

Sobre os autores

Letícia Víer Machado é psicóloga, mestranda no Programa de Pós-Graduação em Psicologia da Universidade Federal de Santa Catarina. Recebe financiamento de pesquisa da CAPES. leticiaviermachado@gmail.com

Rodrigo Ramires Ferreira é psicólogo, mestrando no Programa de Pós-Graduação em Psicologia da Universidade Estadual de Maringá. Recebe financiamento de pesquisa da CAPES. rodrigoramirez1@gmail.com

Paulo César Seron é psicólogo, doutor em Psicologia pela USP - São Paulo, professor Adjunto A do departamento de Psicologia da Universidade Estadual de Maringá. pcseron@uem.br

Recebido em: 04/03/2015

Revisado em: 22/06/2015

Aceito em: 07/07/2015 